\title{
Construction Sites of Sexual Identity: A reading of Emily Rodda's Bob the Builder and the Elves
}

\author{
Elizabeth Parsons
}

$\mathrm{C}$ Uultural conditioning is necessarily prescriptive about the social and sexual scripts offered to particularly the covert ideological positions informing such scripts that I wish to examine in Emily Rodda's popular novel for children, Bob the Builder and the Elves (Rodda 1998). This outwardly innocuous and attractive fantasy story is based around presenting positive stereotypes that aim to shape mildly disobedient children into polite individuals who are able to compromise. John Stephens in his influential text Language and Ideology in Children's Fiction (Stephens 1992) made evident the role that children's books play in such socialising practices. Working from his premise, it is possible to examine the ways in which Rodda's text exploits the perceived malleability of children's psyches by working beneath a fantasy surface to present what are generally deemed appropriate messages and necessary lessons for children. However, at another remove the narrative teaches a number of additional lessons which promote rigidly traditional gender roles and sexual preferences. While the perceived innocence of children's literature has meant that it has long been situated outside the arena of sexual politics, in defiance of this attitude Bob the Builder and the Elves will here be examined as a text committed to endorsing heterosexuality. The story's correlation of heterosexuality with correctness, normality and 'happily ever after' borders on the homophobic.

To read sexual preferences in books designed for prepubescent children could be criticised as somewhat premature. However psychologists and queer theorists alike argue that the childhood experiences recalled by homosexual adults commonly include a sense of alienation and failure that are outcomes of living in societies wherein homosexuality is either hidden or derided. With the exception of texts which are outwardly motivated by issues surrounding sexuality, like the infamous Heather has two Mommies (Newman 1989), reading these biases in literature usually involves interpreting the text beneath its obvious surface. When Kenneth Kidd wrote the introductory essay to the 'Lesbian/Gay Literature for Children and Young Adults' special issue of the Children's Literature Association Quarterly, he registered a level of guilt about these kinds of targeted readings that is, in my view, unwarranted. After offering a well substantiated reading of the homosocial pleasures indulged in by Rat and Mole in The Wind in the Willows, Kidd turns on his own adept reading and labels it 'reductive' (Kidd 1998 , p. 115). He criticises his students who are 'too easily convinced' (Kidd 1998, p.115) by this brand of sophistry. Why is he so coy about this interpretative skillfulness? Kidd goes on to underline what he sees as problematic outcomes of such readings, specifically that they can be misconstrued as suggesting that the text is somehow 'gay.' I am less squeamish about arguing that Bob the Builder and the Elves is an openly heterosexual text. When offering the following interpretation of Bob's relationship to heterosexuality to first year students, I encountered almost equal proportions of those who agreed with my analysis and were dismayed at not having recognized the glaring biases in the text themselves, to students who were completely dismissive of my reading, regarding it as both inappropriate and inaccurate. Since the death of the author, literary theory has privileged the place of the reader in the production of textual meaning, and these kinds of queer readings are no exception. Kidd describes his guilt at projecting my own personal pathology onto the innocent texts' (Kidd 1998, p.115), but it is resisting this brand of innocence that is the premise this paper sets out with. For no text is innocent of ideology.

To begin on the safe surface of Rodda's story, the comic motif central to the text's operation works by way of dissonance. Bob is a blue-singlet-wearing, hairy, tattooed builder's labourer whose house becomes infested by stereotypically feminine elves who threaten to spoil his image with his mates-specifically, they threaten his masculinity. This use of humour both promotes and mocks the stereotypes of hegemonic masculinity which Bob represents. In juxtaposition to Bob, the elves are representative of both femininity and maternity. They are keen on housework and are interested in a level of cleanliness that far surpasses Bob's own concern for such matters. Housework is traditionally coded as teminine, but in the elves' case this sense is heightened by their penchant for floral details, like a vase of flowers on the kitchen table and rose petals strewn in the bath. They make lunches for Bob that involve fairy bread and fairy 
cakes, which he finds very embarrassing when they are revealed to his work-mates. When I asked an eleven year old reader why Bob was so embarrassed by the content of his lunch-box, she responded with the acute observation: 'Durr! Because he's a guy!' This knowledge of what is appropriate to gender is integral to the comic juxtaposition of feminine versus masculine.

Another facet of this comedic thrust is equally relevant to the allegory of conflict resolution which impels the text. Beyond entertainment, the story offers a moral concerning human behaviour: that politeness and compromise are the best solution to Bob's problem. These useful life-skills are deftly tucked beneath the comic surface of the narrative presumably so as not to alienate children with a didactic and prescriptive sermon. When Bob sets out into the world to solve his problem, readers are amused by his inability to express his problem precisely. His embarrassment leads to a misconstruing of the situation because it causes him to mumble and be misheard by the people from whom he seeks help. This is part of the depiction of social skills encoded in the tale: for a problem to be solved it must be both clearly expressed and clearly defined. Each situation in which Bob asks for help involves his being misheard when he says 'elves.' $\mathrm{He}$ then has to clarify this word and be explicit about the nature of his problem. Another repeated comic motif follows these situations, the next step being that the person whom he asks asks him whether he is sure that the elves aren't in fact 'pixies, gnomes, sprites, fairies, dwarves or leprechauns' (pp. 21, 24,31). Defining the problem is integral to solving it, in the fashion of text-book conflict resolution procedure.

Interestingly, in order to learn such lessons, child readers/ listeners need to relate to Bob, the middle-aged builder's labourer. This is not as far-fetched as it seems because Bob's behaviour seems consistently to infantilise him in the text. He needs to ask competent adults to help him with his problem and imitates them to aid his credibility. Mr. Pesky ponders, 'might be a new breed, mate' (p.24) when considering Bob's elf problem, a comment that Bob recycles and passes off as his own in order to impress Lily when he describes his problem to her at the library. He makes only a minor variation: 'Could be a new breed I reckon' (p.31). In line with this infantilising is Bob's discovery that tantrums involving making loud noise and 'throwing things' (p.16) are of little use in getting rid of the elves. While Bob is child-like, the elves who clean up after him and who make his lunches are, on the other hand, given the role that is usually associated with parents.

That there is conflict between Bob/the child and the elves/ parents is then easily read as allegorical for the stresses in family relationships when children rebel against parental standards. It is only by accepting the care of the parents/ elves, with some consideration of Bob's own agenda, that the conflict can be resolved. The message is compromise. Bob writes a letter that politely accepts the elves' attentions, within certain constraints, and the elves are allowed to continue in their role without having to deal with Bob's tantrums. Read in this light, the allegory can also encompass maturity. The transition from rebellion to acceptance could be read as more pertinent to adolescents, a group older than the book's intended audience. It is by accepting the parental elves that Bob can himself get married and pass into the most satisfactory (by the logic of the text) adult behaviour, his initial bachelor-hood/ immaturity being discarded as outgrown. In this way the conflict that is central to the story can be read more succinctly as being specifically directed to heterosexual relationships as part of its promotion of socially acceptable outcomes.

Equally relevant to this resolution is the distinction made between public and private. The problem that starts at home must also be solved at home, representing a dubious logic for some more extreme problems that begin at home, like abuse, for example. Nevertheless, for the purposes of the lighter matters dealt with in this story, the narrative offers another positive model for children. All Bob's attempts to seek outside help are fruitless, and it is only with the aid of Lily Sweet, the next door neighbour, that a solution is reached. While Lily begins the story as Bob's neighbour, by the narrative's close the single wall that divides their houses has been conquered so that their (somewhat negligible) separateness can be overcome.

There is positive closure on all fronts: the elves are allowed to stay; Bob can have his life outside the house 
untainted by humiliating levels of femininity; his friends (about whose opinion he is very concerned) approve of the new arrangements with regard to the cleanliness of Bob's lounge room, since 'Bob's mates quite liked the house being tidier' (p.69); and, best of all, Bob and Lily's relationship flourishes so that they can get married and live happily ever after. Bob has learnt to explain his problem, seek help, overcome his embarrassment and reach a mutually acceptable compromise. All of this ideological coding is potentially healthy and positive in terms of the messages that it sends to children. But the nature of the representations of gender and class is more problematic. Because it is Bob's masculinity that is threatened by the elves (he'll: 'never live it down' (p.56) if his mates find out about them) the question transmutes into one that considers the kinds of gender roles that are promoted by the narrative.

The names Rodda has chosen for her characters are already heavily coded, even before dialogue and behaviour have been presented. 'Bob the Builder' is deliberately opposed to the purity and femininity attached to the name 'Lily Sweet'. Lily is linked with the elves (whose femininity has been discussed above) by being the cause of their arrival in Bob's life. She confesses to having brought them with her when she moved in next door and posits the theory that they have spread. She is also linked to the elves in having accepted them into her life, and hence to the resolution that will eventually govern the closure of Bob's narrative. Interestingly, the first glimpse of Lily shows her involved in specifically elfish behaviour-that is, doing housework; she is 'hanging out her clothes' (p.9). It is also worth noting Lily's relationship to the elves. She is fond of them, and, given that they are orchestrating her relationship with Bob, it is perhaps telling that the elves have transformed the spell that is supposed to get rid of them 'into a song' (p.54) and that this song is used 'to put their babies to sleep at night. It sounds quite sweet really' (p.54). Perhaps Lily's interest in this specific part of elf behaviour is foreshadowing her own desire for the kind of maternal bliss that Bob has the power to make possible. In these ways both Lily and the elves are linked to notions of matemity.

This profoundly conservative drive in the narrative is heightened by the nature of the representation of gender roles. Bob's accentuated masculinity is most often comic. When he proposes to Lily he uses the distinctly ocker phrase: 'You're a bonza sheila Lil, let's get hitched' (p.73). While the phrase is meant to be amusing, it also buys into the unfortunate stereotype of Australian men as unable to express their feelings appropriately. But at an earlier point in the narrative, Bob's behaviour exhibits a level of hostility that signals a more questionable promotion of male behaviour. He says:

\section{'What! You mean I read that book in a tent for the whole rotten afternoon for nothing?' he shouted. \\ 'You mean whoever wrote that book's a ratbag? A crook?' he clenched his fists, and looked around in rage. 'Where's he hang out? I'll soon show him what's what. That low, miserable...' (p.52).}

This violent passage is accompanied by an illustration of Bob looking particularly menacing, his fist is clenched, his mouth open and his teeth showing in a kind of furious roar. But rather than being textually punished, or at least reprimanded for this atrocious behaviour, the narrative voice kindly excuses Bob saying: 'he wasn't usually violent, but he was quite upset' (p.52). It seems a defence unlikely to hold up in court if Bob had gone through with his threats. The narratorial voice is almost motherly in this phrase. In a real world imagined for the infantilised Bob she might be saying: 'Bob's a bit grumpy this afternoon, because he hasn't had his nap.' However, the overall outcome of this passage in the text is that the hero, Bob, is allowed to exhibit this violence without repercussions. What is this text promoting about male behaviour, and a traditionally female response which is both soothing and maternal?

What is particularly pertinent here is that Lily speaks with the same intent and tone as the motherly narratorial voice. She is equally as maternal and soothing on the page that follows Bob's outburst, explaining calmly that the violence is unnecessary. Given the connection between the elves' parental role, if not more directly maternal role, Lily's connection to them, and her later role in Bob's life as his wife, these relationships add up to the promotion of a suspiciously patriarchal representation of wifely duties. Part of Bob's marriage proposal involves this specific 
correlation of Lily and the elves, he says: 'No elf could take your place' (p.73). That a wife's role is so intricately connected to nurturing, housework and tiptoeing around a potentially violent male involves the promotion of seriously regressive information about gender relationships within marriage.

The marriage also seems to be based on intellectual inequality. Lily is one of the competent adult figures whom Bob asks for help in the narrative. She works in the library, while Bob has never been inside such a place before. He seems barely literate when he requires Lily's help to write a note that politely asks the elves to hide themselves. This imbalance is also part of the questionable representation of class advocated by the narrative. The recognizable quirk of Bob's dialect, using 'me' in place of ' $m y$ ', is representative of a particular class of Australian male who does not fare very well in the narrative's representation of them as inarticulate and stupid. Both Lily and the narrator use standard English in a way that signals Bob's usage as incorrect. In comparison with Bob, Lily is middle-class. She speaks not only correctly but politely, and, moreover, she knows about elves and is thus able to present Bob with the solution to his problem. In this way her class position is privileged over Bob's. The text buys into these anti-Marxist politics most specifically when it tries to settle the differences between Lily and Bob in terms of finance. When Lily mishears Bob saying 'elf' for 'wealth' she responds in her typically conciliatory way by saying "who cares about money anyway?' (p.73). This glossed-over issue seems to be the least of their differences.

Beyond these divisive representations of class, the question that the imbalance between Lily and Bob poses most significantly is: why would charming and intelligent Lily settle for an aggressive and inarticulate life partner who seems to have so little to of fer her? The implication seems to be that she needs a man so that she can get married and have children to sing lullabies to, like the elves whom she finds so endearing. Reading the text another way, the elves and Lily are also linked on a more oblique level. The elves are the force which specifically orchestrates Bob's relationship with Lily. They expose him to the femininity he seems to find so threatening but which he comes to accept by the end of the story in order to consummate a relationship with a woman. Significantly, one of the first jobs the elves are responsible for is cleaning the windows so that Bob can see Lily Sweet in her back yard. This event takes place on the first moming accounted for by the narrative. It is the ability to see Lily for what she is, a possible life-partner, that the elves make possible by their presence in Bob's life. Perhaps they can be read as representing the powerful social force (a force, like the elves, which is difficult to see, difficult to pin down in words, and difficult to overcome) that imposes heterosexual behaviour.

What is most striking with regard to reading the glaring heterosexuality of the text, is that the structure of the narrative works with deliberately gendered pairs. Bob's first attempt to seek help in ridding himself of elves involves a trip to the chemist. The story tells of two women who humiliate Bob and send him away empty handed. The first illustration provided for the chemist shop is laden with symbols of femininity. The advertisements all depict beauty products and the text tells us that the women wear that characteristically female colour, pale pink. A possible reading of the presence of the two shop girls collaborating in their humiliation of Bob's masculinity, is the message that two women together cannot solve Bob's problem. Bob's second trial is with Mr. Pesky, the exterminator. The confusion with Bob mumbling about his problem with elves is misunderstood by Mr. Pesky as 'selves'. He replies: 'Of course we do the job ourselves. Who else? There's only me and my brother here' (pp.23-4). It seems that two men together are not the correct solution either. Bob's next attempt to rid himself of the elves' feminine influence occurs at the library where Lily works. Here Bob is cunningly depicted beneath a sign that describes the real nature of his problem: 'love and romance' (p.29). The words are library markers that order books by genre, but Bob's position in the foreground of the illustration means that the sign hangs directly above him in a way that seems to place him (and his problem) beneath this banner. Bob, unaware of what is obvious to observers of the picture, borrows a different genre of book which seems to hold the instructions for a spell that can rid him of the elves. But there is one catch. 
Bob lacks one of the necessary ingredients, baked beans. He races to the shop but is thwarted. Why? Because Tony the shopkeeper has taken his girlfriend out to the movies on a Saturday night. It is because of this that Bob must deliberately go and visit Lily. I say 'deliberately' because the meeting at the library was accidental. It certainly seems as if events are conspiring to show Bob what sexual course of action he must take in order to succeed within the terms of the narrative.

Perhaps it is arguable that children, even children with homosexual tendencies which they are yet to fully realise, will scarcely be able to deconstruct the text to read the message encoded in these gendered pairs or the significance of the ostensibly insignificant character, Tony's girlfriend. But what I would argue is that this text belongs to, and confirms, larger representative structures in societies that repress homosexuality. I would also argue that such subtleties are not lost on children, even if their impact is at an unconscious level. It seems more likely that they exist at the level accessible to my eleven year old reader who knew that Bob's issues were distinctly a product of gender complications. Interestingly it is by way of the logic of gender that gay and lesbian adults recall their childhood responses to feeling gay; according to psychologist Richard Troiden, in terms of homosexual gender formation, prehomosexual children use 'gender metaphors, to interpret and explain their childhood feelings of difference: the mastery of gender roles, rather than sexual scripts, is emphasized during childhood' (Troiden 1993, p. 196). The very prescriptive depictions of what is appropriate to each gender in Rodda's novel, particularly Bob's unhappiness at the inappropriate gender script embodied by the feminine elves who are publicly attached to him, seem to be part of this model.

What is at stake, then, is that homosexually inclined children describe feeling difference and significant complications in their formative years. Texts like Rodda's which directly promote heterosexuality and are prescriptive about 'appropriate' gender behaviours and desires have the flip-side of contributing to the sense of alienation suffered by homosexually inclined children. The desires important to these children are less than excluded by the narrative, they are directly derided by the narrative structure, as two women together and two men together both fail to offer Bob the correct solution. Perhaps an even more pertinent level of homophobia readable in this text is Rodda's decision to call the fantastic creatures of her story 'elves' when they seem to be related more specifically to 'fairies.' After all, they make 'fairy bread' and cook 'fairy cakes'. So why elves? Perhaps this nomenclature belies a level of anxiety about the current cultural meaning attached to being 'a fairy' which of course is also a derogatory term for a homosexual man. Rodda, in her author's note, recalls the inception of the story as:

One morning my own Bob the Builder (my husband) was talking on the phone, while at the other end of the study I was working on a story about fairies. At lunch Bob's conversation was full of bricks and mortar, and mine of wings and wands. The contrast was very funny. It was then that I decided for a big tough bloke, a plague of elves would be just as bad as a plague of cockroaches would be to me.

The narrative's deliberate side-step of the more pertinent term 'fairies,' which Rodda uses here, seems to hint at a level of anxiety about the homosexuality encoded in the word because, in terms of Rodda's description of the humour being bound up in the 'contrast,' there is more contrast to be exploited between the usually female and 'pretty' fairies than the more likely to be male (as in Grimms') elves. Perhaps this anxiety is played out in the narrative when Bob is with his mates at the building site. The embarrassment he feels about their teasing his 'fairy' lunch is suggestive of a male social group's humiliation of homosexual tendencies. Bob goes to great lengths to hide this feminised and therefore (by the layman's logic of his companions, potentially homosexual) aspect of himself. The end of the story could be read against the simple solution of a conflict resolved and a 'happily ever after,' as being rather that Bob must successfully repress, or at least comprehensively hide, the traces of female or homosexual behaviour he has accepted in private (this acceptance is regularly embodied in the story by the way he eats the fairy bread almost unconsciously and this same bread is both comforting and enables him to think 
clearly). In order to maintain his macho exterior with his community of male friends he must keep these things hidden, perhaps to the degree of getting married, a traditional antidote to criticisms of homosexual tendencies.

There is no chance for Bob to come out of the closet either with regard to liking feminine things or being gay. In terms of gayness, his world before the problems posed by the narrative is completely male oriented - a bachelor with only male friends. But, by the end of Rodda's story, Bob has been comprehensively subsumed by a heterosexual and patriarchal order. The allegory of the elves in this reading then shifts, so that from being the powerful socialising force that pushes Bob towards Lily, they become the signifiers of homosexuality itself. They are responsible for confusing Bob's gender preferences by attaching non-masculine things to him. In terms of this kind of reading, the spell that Bob wants to use to rid himself of the elves involves a sequence in which he hides in the tent, locked away from the elves in order to sort out the relevant course of action. The spell also involves putting his head in a sack (p.36). These closeting motifs could be seen as signaling a level of denial about the elves and the homosexuality, or gender difficulties, they represent. My earlier comment outlined the way in which, according to psychologists, both lesbians and gay males see their own gender-inappropriate behaviours and interests in childhood as contributing to their sense of marginality (Troiden 1993, p.197). While Rodda's narrative doesn't allow this head-in-the-sack behaviour to be part of the text's final solution, denial is most certainly Bob's solution in terms of his relationships with other men. He must suppress all external clues, such as being seen eating the wrong food and being conspicuous in showing attention to details of personal appearance (clean boots and hard-hat) because both behaviours might expose his femininity or homosexuality to his friends.

This solution offered by the text is made most evident in Bob's final note written to the elves, which requests that they absent themselves when his mates visit, and also that they ensure that Bob's clothing and lunch-box contents do not give away their presence in his life. These concerns seem to belong to the popular and recognisable taunts which attribute gayness to men. The food angle harks back to the 80 s Australian anxiety about men whose culinary preference was dubious. The slogan 'feed the man meat' is part of this dialectic and in the mid-eighties, comedian 'George Smellavitch' made famous the line: 'I'm so tough I eat quiche in front of truck drivers.' Likewise, the homosexual coding of external appearance is described by Robert Dessaix in his reminiscence about his mother warning him to 'keep a weather eye out for men wearing socks and sandals' (Dessaix 1994, p.14) who were likely to be sexually deviant and desire him as a young boy. Such extemal signals must be avoided if the subject wishes to avoid being labeled homosexual. In Rodda's novel, perhaps it is more circumspect to refer to this by degree. Bob's mates are seen accepting a small level of femininity in terms of appreciating the new cleanliness of Bob's house, but they certainly never see the elves who are actually responsible for it. This conscientious hiding of the elves (in the public sphere of Bob's life) runs in contradistinction to the way in which Bob himself has finally accepted the elves and the femininity or gayness they represent. After an internal struggle, he is finally unable to go through with getting rid of them altogether and learns to appreciate, albeit privately, what they have to offer him.

The internal torment of this struggle, and Bob's initial anxiety about the elves, is so deep-rooted as to suggest the Kristevan abject. When the elves laugh, 'it sends shivers up Bob's spine' (p.11); this is the response of one Kristeva would call an 'I' whose

...mute protest of the symptom, shattering violence of convulsion that, to be sure, is inscribed in the symbolic system, but in which, without either wanting or being able to become integrated in order to answer to it, it reacts, it abreacts. It abjects. (Kristeva 1982, p.3)

Bob's shiver is a physiological response to what is unbearable and, as such, it belies the extent of his anxiety about the elves and their position beyond the acceptable in terms of his known symbolic codes-for Bob, these codes are strictly heterosexual and patriarchal. It is telling, then, that Bob's anxiety cannot be articulated, as we see on numerous occasions in Bob's quest while he mumbles and is misheard. Thus what is external to the symbolic 
order belongs to the abject space of bodily refusal. This abject also constitutes the repulsive force which makes whole the ' $I$ ', by separating individual identity from what it refuses. According to Kristeva it is thus that we know ourselves and thus that our culture knows itself. For Bob, it is a less consciously recognized phenomenon but none the less easily readable in his cultural circumstances. Even more compelling is the tension exhibited by this shiver on the one hand, and Bob's almost unconscious eating of the fairy bread on the other. He seems to be on unstable psychological ground in these opposed physical responses.

Charges will perhaps be laid against this reading on the grounds that it seeks for too much, that it imposes a view unintended by the author and one that goes unnoticed by the children who make up the text's largest audience. But this is not to say that these messages and anxieties are absent from the text. As I argued earlier, ideology's most powerful aspect is its hidden nature and the subtlety of its messages. Interestingly, few adult readers would contest the existence of the text's underlying messages about politeness and compromise, but if you ask the children in the age-group appropriate to the implied audience what the story is about it is unlikely that they will identify these messages as part of the book's content. What I am suggesting is that children are likely to be equally unaware, on a conscious level, of the gender and sexuality messages, but that is not to say that they do not exist or that they cannot infiltrate the child's psyche on other less easily definable levels. Perhaps contrary to the tone in which I am arguing, this critique is not rallying for a book burning. What I am suggesting is that by identifying the ideological tensions in the texts we offer to children we can balance these kinds of representations appropriately. Given that psychologists claim that sensitisation to homosexuality occurs before puberty (Troiden 1993, p.198), it is important to encourage a society in which alternatives are accepted and not only given voices, but also given warm receptions so that prehomosexual children are not alienated by social structures. The other side of this is that heterosexually centered children can mature into adolescents and adults who can be receptive to and understanding of such differences. Presumably this is what we are striving for when as John Stephens claims, we use literature to teach children "how to live in the world' (Stephens 1992, p.8).

\section{REFERENCES}

Dessaix, R. (1994) A Mother's Disgrace. Sydney, Angus \& Robertson.

Kristeva, J. (1982) Powers of Horror: An Essay on Abjection. Trans. Leon S. Roudiez, New York, Columbia University Press.

Kidd, K. (1998) 'Introduction: Lesbian/Gay literature for children and young adults,' Children's Literature Association Quarterly, '23, 3, 114-119.

Newman, L. (1989) Heather Has Two Mommies. Illust. D. Souza, Boston, Alyson Wonderland.

Rodda, E. (1998) Bob the Builder and the Elves. Illust. Craig Smith, Sydney, ABC books.

Stephens, J. (1992) Language and Ideology in Children's Fiction. London and New York, Longman.

Troiden, R. (1993) 'The formation of homosexual identities' in L. Gamets \& D. Kimmel (eds) Psychological Perspectives on Lesbian and Gay Male Experiences. New York, Columbia University Press.

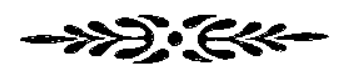

\section{BIOGRAPHICAL NOTE}

Elizabeth Parsons has recently completed her Ph.D in literary studies at Deakin University. Her thesis, entitled: 'Poetry and Silence: a sequence of disappearances', examined Derrida's writings in relation to Helen Keller's lived experience of language and used this comparative study as a theoretical basis from which to read contemporary poetry. She is currently teaching in both children's literature and literature at Deakin University. 